\section{Tea, cake and computers}

\section{A Computer Called LEO: Lyons Teashops and the World's First Office Computer \\ by Georgina Ferry \\ Fourth Estate: 2003. 240 pp. $£ 15.99$}

\section{Anthony Ralston}

At first glance it seems astonishing that a company known mainly for operating cafes that served tea and cakes in Britain should not only have installed the first ever computer for business applications, but should also have built it. But as Georgina Ferry makes clear in this book, it wasn't really so surprising because J. Lyons \& Co. had become, under the leadership of John Simmons, a pioneer in the application of technology to management in the years before the Second World War.

It was therefore natural that two senior Lyons employees, Raymond Thompson and Oliver Standingford, should have been sent to the United States in 1947 to study recent developments in office automation and to learn what they could about ENIAC (the Electronic Numeric Integrator and Computer), which had just been completed at the University of Pennsylvania. (ENIAC was not the first electronic computer - the Colossus of Britain's Bletchley Park deserves that accolade. However, Colossus was designed for a special purpose, codebreaking, and was still a secret in 1947. Indeed, even in the late 1970s, I could not find a British author to write an article on Colossus for an encyclopaedia that I was editing because it was still covered by the Official Secrets Act.)

Thompson and Standingford returned to Britain imbued with the potential of computers for business management. They had learned that, in the United States, only the Prudential Insurance Company was thinking along similar lines. In late 1947 the pair visited the University of Cambridge, where Maurice Wilkes was building the EDSAC (the Electronic Delay Storage Automatic Calculator), and they knew they had found what they needed. Although EDSAC had been designed with scientific and engineering calculations in mind, they believed that its design could be adapted to Lyons' needs.

How this could be done wasn't at all obvious. Most scientific applications tended to be 'compute-bound' - lots of computing and little input or output - whereas business or data-processing applications tended to be 'input/output bound, with lots of input and output but very little computing. Could a computer intended for the former be adapted for the latter? The Lyons management convinced themselves that it could, although serious problems with input and output

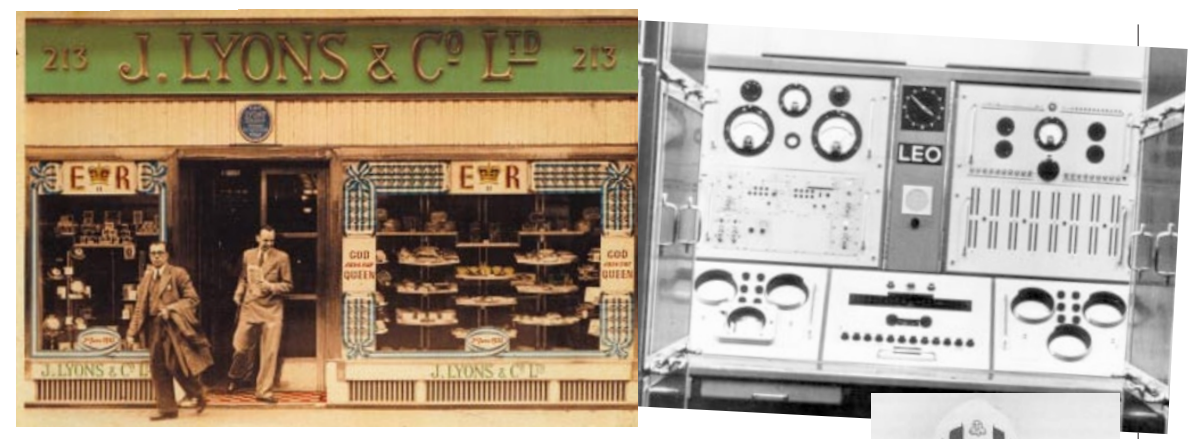

Mane frame? LEO, the first business computer, was set up and run by J. Lyons \& Co., which operated a chain of tea shops in Britain.

bedevilled the LEO (Lyons Electronic Office) project for much of its lifetime.

LEO was, essentially, a copy of the EDSAC with a few hardware innovations and some limited software advances. Its main claim to fame is in the applications area. On 29 November 1951, LEO ran the first ever business application, a program to calculate the value of Lyons' output of bread, cakes and pies. This was long before any similar application in the United States, Prudential's use of computers having been delayed by hardware problems. Over the following years, LEO took over much of Lyons' dataprocessing work, and was used for some non-Lyons applications, including various defence-related calculations. When LEO executed defence programs, the Official Secrets Act required it to be encircled by red tape, with only authorized personnel allowed near the computer.

It was particularly quixotic of Lyons not only to build and install their own machine but also to go into the business of building and selling computers to others. An updated version, LEO II, still used valves; LEO III was redesigned to incorporate semiconductor technology. Ten LEO IIs were delivered to customers between 1957 and 1961, and 61 LEO IIIs were sold, mainly from 1962 to 1966 . By then, the manufacturing and marketing power of US companies, particularly IBM, was severely impairing the ability of Lyons to compete as an independ-

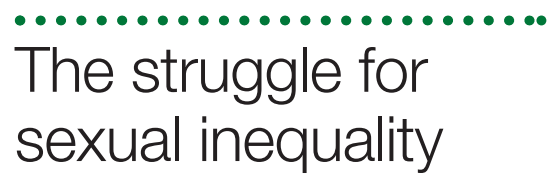

Sex Wars: Genes, Bacteria, and Biased Sex Ratios

by Michael E. N. Majerus

Princeton University Press: 2003. 280 pp.

$\$ 45, £ 29.95$

\section{Göran Arnqvist}

In the first edition of On the Origin of Species, Charles Darwin made a brave and essentially correct attempt to explain the striking rule that males and females occur ent manufacturer of computers. In 1963, Leo Computers was merged with - but effectively taken over by - the computer division of English Electric, in the first of a series of mergers that eventually led to the creation of the last major British computer company, International Computers Ltd.

The story of LEO has already been told in two more technical books: LEO: The First Business Computer by Peter Bird (Hasler, 1994) and LEO: The Incredible Story of the World's First Business Computer by David Caminer et al. (McGraw-Hill, 1997); further information can be found on the web at www.leo-computers.org.uk. But Georgina Ferry tells the story well, with less technical detail but with nice capsule histories of the development of computing in Britain and the United States, particularly in the decade after the end of the Second World War. Her book is rather more accessible to the general reader than the others, and is a good read for anyone interested in LEO or, more generally, in postwar computing in Britain.

Anthony Ralston is professor emeritus of computer science and mathematics at the State University of New York at Buffalo, and an academic visitor in the Department of Computing, Imperial College, London SW7 2BZ, UK.

in equal numbers. In later editions, however, he described the problem of the even sex ratio as being "so intricate that it is safer to leave its solution to the future". Ronald Fisher took up this challenge in 1930, noting that every offspring has one mother and one father. Therefore, the sexes on average fare equally well in passing their genes on to the next generation under an even sex ratio. Fisher realized that a mother that produces an excess of the rarer sex (whichever this may be) will be favoured by natural selection. So, like a pendulum in motion that eventually comes to rest, the sex ratio will stabilize at equal numbers of the sexes over evolutionary time. But there are many 
exceptions to this rule, and understanding them has proved to be a challenge for evolutionary biologists.

These exceptions form the centre of gravity of Sex Wars. Michael Majerus of the University of Cambridge starts off by walking us through the background and some of the basics: asexual versus sexual reproduction, sexual selection, the sex-determining mechanisms, the sex ratio and the various 'economic' factors that can lead to uneven sex ratios are all covered in the opening sections. But the bulk of the book is about the various genetic conflicts that knock the sex ratio off its evolutionary equilibrium.

For a gene located on a nuclear autosome - any chromosome except the sex chromosomes - life is as good in a male as it is in a female, in terms of the probability of being transmitted to the next generation. For extranuclear genes, however, males are a genetic dead-end because the sperm contributes nothing but its nuclear genes to the fertilized zygote. Cytoplasmic genes located in mitochondria or in endocellular microorganisms are expected to favour the female line, through which they are transmitted to the next generation.

This sets the stage for a battle between autosomal genes on one hand, and genes with unequal transmission rates in the two sexes on the other. I found the portrayal of these opponents by Majerus very exciting, and his account of them offers many insights. These evolutionary law-breakers use a variety of intrusive tactics (including killing sperm containing Y chromosomes, transforming genetic males into functional females, or simply killing males), which all bias the sex ratio towards females, sometimes even to the point when the 'host' is driven close to the brink of extinction because of a lack of males in the population. The autosomal genes fight back, however. Majerus describes several cases of autosomal 'rescue' genes that counter the effects of the lawbreakers. The natural history of sex-ratio distortion is the definite strong point of this book - Majerus tells many intriguing and entertaining tales about various reproductive curiosities.

No book can be written for everyone, but every book should be written for someone. This book is aimed at "a wide audience". Any reader of this book will find much of interest, but will also be frustrated. Like the indecisive Buridan's ass who could not choose between two equal bales of hay and therefore starved to death, Majerus roams the treacherous no-man's-land that lies between the general reader and the specialist, unable to quite reach either. General readers will stumble over many of the terms and turns in the more detailed and complicated sections. There is a glossary at the end of the book, but it is incomplete and partly confused.

Specialist readers, on the other hand, will

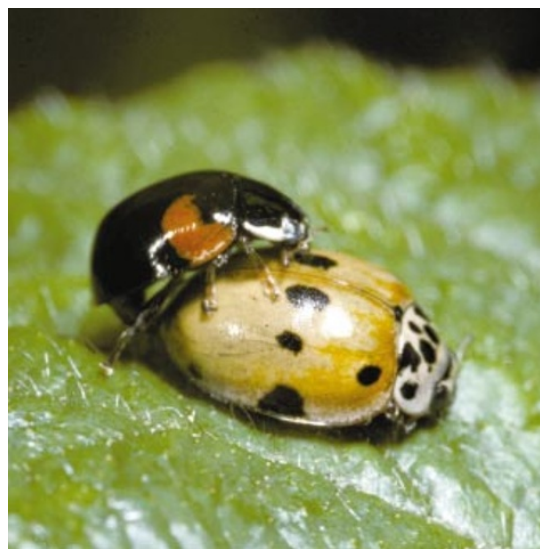

Sex to die for: females of the ladybird Adalia 10-punctata distort the sex ratio by killing males.

find the lack of reference to many case studies and ideas, as well as some more technical problems, quite annoying at times. They might also find that the book loses the battle with a more exhaustive book on sex ratios Sex Ratios, edited by I. C. W. Hardy (Cambridge University Press, 2002) - that recently reached the bookshelves. If Sex Wars were less technical and more 'popular', it might have found more enthusiastic readers.

Göran Arnqvist is in the Department of Animal

Ecology, Evolutionary Biology Centre,

University of Uppsala, Norbyvägen 18d,

SE-752 36 Uppsala, Sweden.

\section{The next happy pill}

\section{Better Than Prozac: Creating the} New Generation of Psychiatric

\section{Drugs}

by Samuel Barondes

Oxford University Press: 2003. 240 pp.

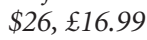

\section{Les Iversen}

The past 50 years have seen a transformation in the practice of psychiatry. The emphasis has moved from psychotherapy with a limited repertoire of drugs that were used only in the most severely ill patients, to the widespread use of drugs that act on the central nervous system (CNS), with psychotherapy being an expensive luxury for a minority of patients. Samuel Barondes is well placed to review the psychopharmacology revolution and to offer predictions for the future, as he has worked through this period as a practising psychiatrist and as an active researcher who has made important contributions to the field.

An early section of the book explains how the existing drugs used to treat psychiatric illnesses — antidepressants, antipsychotic drugs, tranquillizers and amphetamines were discovered, with colourful accounts of the individuals involved. Along the way there

\section{New in paperback}

Mapping Human History: Genes, Race, and Our Common Origins

by Steve Olson

Mariner, \$14; Bloomsbury, £7.99

Our Posthuman Future: Consequences of the Biotechnology Revolution by Francis Fukuyama

Profile, £8.99

The Golden Ratio: The Story of Phi, The Extraordinary Number of Nature, Art and Beauty

by Mario Livio

Review (Headline), £7.99

Nexus: Small Worlds and the Groundbreaking Theory of Networks by Mark Buchanan

W. W. Norton, $\$ 14.95$

"Mark Buchanan gives a cogent and engaging description of recent developments in complex networks." Sidney Redner Nature 418, 127-128 (2002).

The Monkey in the Mirror: Essays on the Science of What Makes Us Human by lan Tattersall

Harvest Books, £13

are explanations in simple language of how the drugs affect various neurotransmitter mechanisms in the brain, and an introduction to the concepts of controlled clinical trials, the placebo effect and the mystery of why it takes many weeks of treatment before the maximum therapeutic benefits of many CNS drugs are seen.

Barondes uses individual case histories to illustrate many of these points, a device that helps to involve the reader with real people who have benefited from drug treatments, and to illustrate some of the shortcomings of the medicines that are presently available. There is a graphic description, for example, of the power of the selective serotonin re-uptake inhibitor (SSRI) Prozac to transform a patient from a state of sadness and agitation to one of calm and tranquility, albeit with a diminished intellectual passion and reduced sex drive.

A second section provides an overview of the prospect that a better Prozac will emerge from current research in this field. Like many others, the author believes that this will come from a better understanding of the nature of the biological disturbances that underlie psychiatric illnesses. There is reason for optimism: several valuable clues have already emerged from research on the genetic risk factors underlying these illnesses, and potential candidate genes have been 